\title{
Diagnostic and Prognostic Interests of Plasmatic Neuroglobin during Stroke in Adult at the Acute Phase
}

\author{
J. F. Nnang Essone1, C. Allognon², R. Nkiema3 ${ }^{3}$, S. R. Aubin Igombé4, P. Nzoghe Nguema4, \\ F. Ovono Abessolo ${ }^{3}$, E. Anyunzok ${ }^{5}$, E. Ngou Milama ${ }^{3}$
}

${ }^{1}$ Department of Physiology, Faculty of Medicine and Health Sciences of Libreville and Department of Emergency Resuscitation Anesthesia of Angondjé University Hospital Center, Libreville, Gabon

${ }^{2}$ Department of Cardiology, University Hospital Angondjé, Libreville, Gabon

${ }^{3}$ Department of Chemistry-Biochemistry, Faculty of Medicine and Health Sciences, University of Health Sciences, Libreville, Gabon

${ }^{4}$ Department of Anesthesia Emergency Resuscitation of Owendo University Hospital, Libreville, Gabon

${ }^{5}$ Department of Mathematics and Biostatistics, Faculty of Medicine and Health Sciences, University of Health Sciences, Libreville, Gabon

Email: jfnnang@gmail.com

How to cite this paper: Nnang Essone, J.F., Allognon, C., Nkiema, R., Aubin Igombé, S.R., Nzoghe Nguema, P., Ovono Abessolo, F., Anyunzok, E. and Ngou Milama, E. (2019) Diagnostic and Prognostic Interests of Plasmatic Neuroglobin during Stroke in Adult at the Acute Phase. World Journal of Neuroscience, 9, 52-70. https://doi.org/10.4236/wjns.2019.92004

Received: February 8, 2019

Accepted: May 11, 2019

Published: May 14, 2019

Copyright $\odot 2019$ by author(s) and Scientific Research Publishing Inc. This work is licensed under the Creative Commons Attribution International License (CC BY 4.0).

http://creativecommons.org/licenses/by/4.0/

\begin{abstract}
Introduction: Neuroglobin (Ngb) owes its name to its preferred location in the nervous system. Its plasma concentration increases during cerebral ischemia. However, the interest of its dosage in the diagnosis and the prognosis of the strokes in the adult is not defined. Objectives: To determine if plasmatic Ngb can be used as a diagnostic biomarker and prognostic for stroke in adults at the acute phase. Population and Methods: This was a prospective study in 69 people, including 39 suspected stroke (Cerebral ischemia or CI, Intracerebral hemorrhage or ICH) and 30 healthy volunteers (controls). The plasma concentration of $\mathrm{Ngb}(\mathrm{CmNgb}$ in $\mathrm{ng} / \mathrm{ml})$ of the patients was determined at admission day (d1), at the third day (d3) and seventh day ( $\mathrm{d} 7)$. CmNgbtaken at $\mathrm{d} 1$ was compared between patients and controls. Its evolution over time, as well as its relation with the clinical parameters, including the Glasgow coma scale and the short-term mortality in stroke subjects was analyzed by the Mann and Whitney tests and the Wilcoxon test $(p<0.05)$. Results: At d1, the CmNgb of all types of stroke was $3.140 \pm 2.700$ $\mathrm{ng} / \mathrm{ml}$, and did not differ significantly from controls $(0.303 \pm 0.114 \mathrm{ng} / \mathrm{ml}, \mathrm{p}=$ 0.070). On the other hand, it was higher in CI victims $(5.800 \pm 0.720 \mathrm{ng} / \mathrm{ml})$ than in ICH $(1.750 \pm 0,090 \mathrm{ng} / \mathrm{ml})(\mathrm{p}=0.030)$. It then decreased on $\mathrm{d} 3$ in CI victims $(2.600 \pm 0.112 \mathrm{ng} / \mathrm{ml})$ and $\mathrm{ICH}(0.420 \pm 0.211 \mathrm{ng} / \mathrm{ml})$, returning to normal on $\mathrm{d} 7(0.420 \pm 0.200 \mathrm{ng} / \mathrm{ml}$ for Cl's, $\mathrm{p}=0.001$, and $0.360 \pm 0.300$ $\mathrm{ng} / \mathrm{ml}$ for ICH, $\mathrm{p}=0.002$ ). There was a relationship between $\mathrm{CmNgb}$, delay of
\end{abstract}


occurrence of the first symptoms of the stroke $(3.140 \pm 2.700 \mathrm{ng} / \mathrm{ml}$ before the 6th hour, and $0.643 \pm 0.244 \mathrm{ng} / \mathrm{ml}$ after the 6th hour $(\mathrm{p}=0.003)$ and the volume of the hematoma $(p=0.0027)$. None relationship existed between $\mathrm{CmNgb}$, Glasgow coma scale $(\mathrm{p}=0.427)$ and short-term mortality $(\mathrm{CmNgb}=$ $3.95 \mathrm{ng} / \mathrm{ml}$ in survivors versus $2.65 \mathrm{ng} / \mathrm{ml}$ in deceased $\mathrm{p}=0.060$ ). Conclusion: This study shows that the plasma concentration of Neuroglobin is high during stroke in humans in the acute phase. This elevation follows triphasic kinetics and appears to be more important during infarction than hemorrhage. These results suggest that $\mathrm{CmNgb}$ can be used as a diagnostic marker for stroke in adult at the acute phase, by differentiating ischemia from hemorrhage. However, this work needs to be confirmed on a larger sample of patients.

\section{Keywords}

Neuroglobin, Stroke, Diagnosis, Prognosis

\section{Introduction}

Neuroglobin (Ngb) is a protein discovered in 2000 by Burmester et al. [1] [2]. It owes its name because of its preferential expression in the nervous system [1] [2] [3]. It is a protein that derives from an old branch of globin more than 600 million years ago [1] [2]. Ngb was initially identified from the nucleic databases of mouse and human brains [1]. At present, the exact biological functions of Ngb as well as its mechanisms of action remain poorly known. However, by the fact that its plasma concentration increases of hypoxia situation [1]-[10], especially of cerebral [1] [2] [3] [11] [12] [13] and retinal ischemia [14] [15] [16] [17], most authors attribute to him neuroprotective properties. Among these neuroprotective functions [1] [2] [3], the anti-oxidant [1] [2] [3] [18] [19] and anti-apoptotic effect [20] [21] are particularly noteworthy. One of the mechanisms involved in these processes seems to be in relation by mitochondrial oxidation pathways, the regulation of which would be via hypoxia inducible factor-1 alpha (HIF-1 alpha) [1] [22].

As part of neuroprotection during acute cerebral infarction, Ngb has been widely evaluated from other vertebrates, but very little in humans [13] [23] [24] [25] [26] [27]. Indeed, in rodents, it has been shown that stroke induced after carotid occlusion is responsible for high plasmatic concentration of Ngb. The authors suggested a role of diagnostic biomarker and monitoring of this protein during acute stroke [1] [2] [3] [13]. In the human, two studies done by Jin et al in 2010 and 2013 had noted overexpression of Ngb, respectively in infarcted area of $\mathrm{CI}$, and in peri-hematoma area during ICH secondary to a rupture of venous arterial malformations. According to them, these results supported the neuroprotective role of $\mathrm{Ngb}$ during ischemic events in the central nervous system, including stroke [13] [23] [24] [25] [26] [27]. Stroke (Cerebral infarction or CI, and intracerebral hemorrhage or ICH) is a common pathology in Africa 
[28]-[33]. It may be complicated by hypoxia and/or focal or general cerebral ischemia, whether acute or secondary depending on the type and severity. Inflammatory phenomena associated with the apoptosis process in infarcted and peri-infarcted zones have been described [34] [35] [36]. Currently, brain imaging remains the best way for diagnosis, therapeutic, monitoring and prognosis [34] [35] [36] [37]. In recent years, several research teams have been working on the demonstration of biomarkers which, in support of brain imaging techniques, would allow a much faster diagnosis, but above all more precise in terms of etiopathogenesis and pathophysiology. However, most of these studies have not yet resulted in consensus [38] [39] [40] [41]. Also, we wondered whether Ngb could be a biological marker, in addition to clinical examination and medical imaging, for the initial diagnosis and prognosis for stroke in adult at the acute phase.

\section{Population and Methods}

\subsection{Population}

This was a prospective study, conducted in Libreville (Gabon), from January 2016 to January 2017 included. The recruitment of people suffering from stroke (anamnesis, general examination, neurological, brain scan) was carried out in the emergency, resuscitation and neurology departments of the main university hospitals in Libreville. Volunteers (healthy people or controls), after anamnesis, general and neurological examination were selected from the general population in voluntary mode. The neuroglobin assay was done at the biochemistry laboratory of the Libreville University of Health Sciences. This investigation was conducted taking into account the principles of medical ethics according to the Helsinki Declaration [42]. The authorizations of the responsibilities in charge of the units in which the study had been carried out were obtained. In addition, volunteers and parents of patients were assured of the confidentiality of the data collected.

\subsubsection{Inclusion Criteria}

As soon as they are hospitalized in the service, and after obtaining informed consent from the parents or the stroke subjects themselves, patients aged 18 to 65 , regardless of sex, suspected of having a stroke (according to [34]), less than 48 hours old, were included. At the same time, volunteers (controls), with the same socio-demographic criteria as the patients and whose clinical evaluation (anamnesis, general and neurological examination) were normal, were included.

\subsubsection{Non Inclusion Criteria}

On the other hand, all persons having pathologies or taking drugs likely to modify the plasma concentration of neuroglobin [43] (disease of the nervous system other than acute stroke, renal failure, taking of deferoxamine, cobalt, cinnamic acid and valproic) had not been included. 


\subsection{Methods}

\subsubsection{Recruitment of the Study Population}

Upon admitted to the different departments (resuscitation or neurology) for suspicion of stroke, the patients had a clinical examination (anamnesis, general and neurological examination) carried out by a neurologist and a resuscitator. This evaluation made it possible to look for the clinical signs in favor of a stroke [34], and subsequently to establish the prognostic scores such as, the Glasgow coma scale according to Teasdale and Jennet [44], the Four score (Full out line of unresponsiveness score) developed by Wijdicks et al. [45], and the score of the World Federation of Neurosurgical Societies (WFNS score) [46]. For the plasmatic dosage of $\mathrm{Ngb}$, blood samples were taken from the veins of the forearm on ethylene thiamine tetra acetic tube (EDTA), for a volume of $5 \mathrm{ml}$ of blood per tube. The blood tests were performed at admission (d1), concomitantly with the routine checkup (blood count, blood ionogram, uremia, serum creatinine, serum uric acid, blood glucose, prothrombin time and activated cephalin time), at the third (d3) and seventh day (d7). The blood, once collected in the tubes, was transported in a cooler (Prince ware ${ }^{\mathrm{TM}}$, USA) to the biochemistry laboratory. Plasma obtained immediately after centrifugation (Universal $320^{\mathrm{TM}}$, Hettich ${ }^{\oplus}$ Zentrifugen, Germany) was placed in cryotubes (Biologix ${ }^{\mathrm{TM}}$, Biologix group ${ }^{\circ}$ Ltd., China) then stored in a refrigerator (Forma 900 series $^{\mathrm{TM}}$, Thermo Scientific $^{\oplus}$, USA) at $-80^{\circ} \mathrm{C}$. Upon the patient was conditioned, depending on the place of recruitment, he had a brain scan without injection (Philips ${ }^{\mathrm{TM}}$, Philips ${ }^{\oplus}$ USA) or (Neusoft ${ }^{\mathrm{TM}}$ Neusoft medical system ${ }^{\circledR}$, USA). This imaging made it possible to determine the type of stroke (Ischemia or hemorrhage), the subgroup and caracteristics of ICH (volume of intracerebral hematoma in $\mathrm{mm}^{3}$, subarachnoid hemorrhage or SAH), and the establishment of specific gravity scores for stroke (Fisher [47] and Hemphill JC scores [48]). Short-term mortality was determined during the first seven days of hospitalization for all patients selected for the study.

The volunteers were recruited consecutively, by direct matching with patients, according to age and sex. Once verbal agreement obtained with each of them, an appointment was given to them in one of the pre-anesthesia consultation rooms of the University Hospital of Libreville for the clinical evaluation (Anamnesis, general and neurological examination) and the blood sample. Instead of the appointment, after signature of the consent, a single blood test was made at a peripheral vein of the forearm, in the same way as the patients. The blood, after being taken from an EDTA tube, was then sent to the Faculty of Medicine's Biochemistry Laboratory where it was conditioned and stored using the same procedures as in patients.

In all participants, the data from the clinical and paraclinical evaluation were subsequently recorded in a medical file. In the stroke, these were epidemiological (age in year, gender, history of hypertension), clinicals (delay presumed occurrence of the first symptoms of stroke, especially, occurrence before the 6th hour, or after 6th hour following hospitalization), paraclinics (type and nature of 
stroke using cerebral CT, i.e. ICH, CI, SAH, volume of intracerebral hematoma measured by brain scan in two groups $<30 \mathrm{~mm}^{3}$, $>30 \mathrm{~mm}^{3}$; the plasma concentration of $\mathrm{Ngb}$ in $\mathrm{ng} / \mathrm{ml}$ and its kinetics during the first seven days of hospitalization by the determination of $\mathrm{Ngb}$ at $\mathrm{d} 1, \mathrm{~d} 3$ and $\mathrm{d} 7$ ), as well as prognosis (short-term mortality by determining theoutcome on the 7th day of stroke, especially survivor and deceased; mean of Glasgow coma scale on day 1; mean of the Hemphill, WFNS, Fisher and Four scores during d1, d3 and d7) as well as prognosis (Glasgow, Hemphill, WFNS, Fisher and Four scores, established respectively at admission, $\mathrm{d} 1, \mathrm{~d} 3$, and $\mathrm{d} 7$ ), short-term mortality (i.e. during the first 7 days of hospitalization).

\subsubsection{Dosage of Plasmatic Neuroglobin}

The Ngb was assayed using a previously parameterized automaton (Elisys Un$\mathrm{o}^{\mathrm{TM}}$, Human $^{\oplus}$, Germany) using the ELISA technique. To do this, an Elabscience ${ }^{\circ}$ KIT ELISA kit was used. The assay technique used in this study was previously described in the user manual provided by Elabscience ${ }^{\circledast}$ [49]. To begin with, 100 microliters of serum was placed in the wells containing the anti-Ngb monoclonal antibody. The plate was then covered with cellophane adhesive film and incubated for 90 minutes at $37^{\circ} \mathrm{C}$. After this incubation and removal of the liquid, 100 microliters of $\mathrm{AB}$ detection biotinylated working solution was added and the wells were again covered and reincubated for at least 1 hour at $37^{\circ} \mathrm{C}$. Following this incubation, the wells were washed 4 times with 350 microliters of wash buffer. At the end of this treatment, 100 microliters of peroxidase [HRP] were placed in each well, followed by another incubation at $37^{\circ} \mathrm{C}$ for 30 minutes. At the end of this treatment, five washing operations were performed as before, then 90 microliters of substrate were added to each well. Thirty minutes later, the solution turned blue, then 50 microliters of the stopping solution was put into each well. The optical density was then measured on a Biorad ${ }^{\oplus} \mathrm{PR} 3100^{\mathrm{TM}}$ reader. The concentration of $\mathrm{Ngb}$ was obtained by comparison with a standard range treated at the same time as the samples.

\subsection{Statistical Analysis}

This investigation used a convenience sample. The study population consisted of 69 people, including 30 controls and 39 patients. The data, upon collected, was then entered on a Microsoft Excel $2010^{\circ}$ file and analyzed using the EPI INFO $7^{\circ}$ software of Center for diseases control. The descriptive analysis was based on the calculation of means, medians, proportions and standard deviations. The comparison of proportions and means was based on the chi-square test. Spearman's test allowed us to study the correlations between $\mathrm{CmNgb}$ and quantitative variables. The relationships between quantitative and qualitative variables were analyzed by the Mann and Whitney test and the Wilcoxon test $(\mathrm{p}<0.05)$.

\section{Results}

Of the 69 recruited, including 39 suspected stroke and 30 controls, there were 47 
men and 22 women (ratio $\mathrm{M} / \mathrm{W}=2.13$ ). The epidemiological and clinical parameters, the stroke type's, the intracerebral hematoma volume, as well as the $\mathrm{CmNgb}$ of the 39 persons victims for stroke are summarized in Table 1.

Men accounted for $72.80 \%(n=28 / 39)$, while $28.20 \%(n=11 / 39)$ were women. The mean of age of the stroke population was $49 \pm 12.5$ years [18]-[63]. Of the 39 suspected strokes, 25 were found to have arterial hypertension (64.10\%), while 23 (59\%) arrived at the hospital during the first 6 hours after the delay presumed occurrence of the first symptoms of stroke.

Table 1. Epidemiological and clinical parameters of general population, stroke and their subgroups (CI and ICH).

\begin{tabular}{|c|c|c|c|c|c|}
\hline \multicolumn{6}{|c|}{ Types of population } \\
\hline Parameters & General population & Volunteer & Stroke & $\mathrm{CI}$ & $\mathrm{ICH}$ \\
\hline \multicolumn{6}{|l|}{ Gender (Number/\%) } \\
\hline Men & $39(56.50)$ & $11(36.60)$ & $28(72)$ & $5(38.40)$ & $18(69.20)$ \\
\hline Women & $30(43.40)$ & $19(63.40)$ & $11(28)$ & $8(61.50)$ & $8(30.70)$ \\
\hline Mean age \pm standard deviation & $48 \pm 12.00$ & $40 \pm 11.30$ & $49 \pm 15.50$ & $52 \pm 1.30$ & $48 \pm 3.80$ \\
\hline \multicolumn{6}{|l|}{ History of arterial hypertension (Number/\%) } \\
\hline Yes & $27(39.16)$ & & $25(64.10)$ & $13(100)$ & $12(46.10)$ \\
\hline No & $42(60.87)$ & & $14(35.90)$ & $0(0.00)$ & $14(53.90)$ \\
\hline \multicolumn{6}{|l|}{ Subgroups of ICH (Number/\%) } \\
\hline ICH (Intra cerebral hematoma) & $21(30.43)$ & & $21(53.84)$ & 0.00 & $21(80.76)$ \\
\hline SAH (Subarachnoid hemorrhage) & $5(7.24)$ & & $5(12.82)$ & 0.00 & $5(19.23)$ \\
\hline \multicolumn{6}{|c|}{ Delay presumed occurrence of the first symptoms of stroke } \\
\hline Before the $6^{\text {th }}$ hour & - & & $23(59)$ & & \\
\hline After the $6^{\text {th }}$ hour & - & & $16(41)$ & & \\
\hline \multicolumn{6}{|l|}{ Vital Parameters (Mean \pm standard deviation) } \\
\hline Glasgow coma scale (3 - 15) & & $15 \pm 1.20$ & $13 \pm 2.80$ & $13 \pm 10.1$ & $11 \pm 2.10$ \\
\hline Heart rate (pulse/min) & & $93 \pm 18.90$ & $70 \pm 3.50$ & $110 \pm 3.2$ & $95 \pm 13.20$ \\
\hline Sp02 (in \%) & & $98 \pm 3.70$ & $99 \pm 10.10$ & $98 \pm 3.8$ & $98 \pm 20.40$ \\
\hline Systolic arterial blood pressure (mmHg) & & $130 \pm 20$ & $191.6 \pm 40$ & $200 \pm 1.2$ & $180 \pm 3.20$ \\
\hline Diastolic arterial blood pressure $(\mathrm{mmHg})$ & & $82 \pm 3.10$ & $112 \pm 25.30$ & $120 \pm 3.5$ & $100 \pm 5.80$ \\
\hline \multicolumn{6}{|l|}{$\begin{array}{l}\text { Specific prognostic scores for stroke } \\
\text { (Mean } \pm \text { standard deviation) }\end{array}$} \\
\hline Four $(0-16)$ & & & & 15 & \\
\hline $\mathrm{ICH}(0-6)$ & & & & & 3 \\
\hline Fisher $(0-4)$ & & & & & 2 \\
\hline WFNS $(1-5)$ & & & & & 3 \\
\hline \multicolumn{6}{|l|}{ Outcome on the 7th day of stroke (Number/\%) } \\
\hline Survivor & & & $21(53.80)$ & 9 & 12 \\
\hline Deceased & & & $18(46.20)$ & 4 & 14 \\
\hline
\end{tabular}


Table 2. Comparison of CmNgb between stroke victims and controls, relationship between CmNgb, epidemiological, clinical, paraclinical and prognosis parameters of stroke subjects.

\begin{tabular}{|c|c|c|c|c|}
\hline Parameters & $\begin{array}{l}\text { Number } \\
\text { (n) }\end{array}$ & $\begin{array}{l}\mathrm{CmNgb} \\
(\mathrm{ng} / \mathrm{ml})\end{array}$ & $\begin{array}{c} \pm \text { Standard } \\
\text { Deviation of } \mathrm{CmNgb}\end{array}$ & $\mathrm{p}$ \\
\hline \multicolumn{5}{|l|}{ Type of population } \\
\hline General population & 69 & 1.400 & 1.670 & \\
\hline volunteers & 30 & 0.303 & 0.114 & 0.070 \\
\hline Stroke & 39 & 3.140 & 2.700 & \\
\hline \multicolumn{5}{|c|}{ Number of stroke subgroups ( $\mathrm{CI}$ and $\mathrm{ICH})$} \\
\hline CI (Cerebral infarction) & 13 & 5.800 & 0.720 & 0.030 \\
\hline ICH (Intra cerebral hematoma) & 26 & 1.750 & 0.090 & \\
\hline \multicolumn{5}{|c|}{ Epidemiological characteristics of the working population } \\
\hline \multicolumn{5}{|l|}{ Gender in volunteers } \\
\hline Men & 19 & 1.020 & 1.810 & 0.9750 \\
\hline Women & 11 & 1.300 & 1.200 & \\
\hline \multicolumn{5}{|l|}{ Gender in stroke } \\
\hline Men & 28 & & & \\
\hline women & 11 & & & \\
\hline \multicolumn{5}{|c|}{ History of arterial hypertension in stroke } \\
\hline Yes & 25 & & & 0.9750 \\
\hline No & 14 & & & \\
\hline \multicolumn{5}{|l|}{ Clinical parameters } \\
\hline \multicolumn{5}{|c|}{ Delay presumed occurrence of the first symptoms of stroke } \\
\hline Before the $6^{\text {th }}$ hour & 23 & 3.140 & 2.700 & 0.003 \\
\hline After the $6^{\text {th }}$ hour & 16 & 0.643 & 0.244 & \\
\hline \multicolumn{5}{|l|}{ Glasgow coma scale in stroke } \\
\hline Patient with score $\geq 3-13 / 15$ & 15 & & & 0.427 \\
\hline Patient with score $\geq 13-15 / 15$ & 24 & & & \\
\hline \multicolumn{5}{|c|}{ Volume of intracerebral hematoma in ICH subjects } \\
\hline$<30 \mathrm{~mm}^{3}$ & 17 & 1.21 & 0.75 & 0.0027 \\
\hline$>30 \mathrm{~mm}^{3}$ & 9 & 2.16 & 0.375 & \\
\hline \multicolumn{5}{|c|}{ Outcome of stroke victims on the 7th day } \\
\hline Survivor & 21 & 3.95 & & 0.060 \\
\hline Deceased & 18 & 2.65 & & \\
\hline
\end{tabular}

For vital parameters, the mean of Glasgow coma scale was $13 \pm 1.20$ [3]-[15]. The mean of systolic and diastolic blood pressure were $191.60 \pm 40.10 \mathrm{mmHg}$ [276 - 110] and $112.30 \pm 25.30 \mathrm{mmHg}$ [180 - 70]. The mean of pulse oxygen saturation was $98 \pm 3.70 \%(86 \%-100 \%)$, while the heart and respiratory rate were $92 \pm 18.90$ [55 - 155] and $14 \pm 4.30$ [9]-[36] respectively (Table 1). The outcome of stroke during the first week of admission (resuscitation or neurology) was 
unfavorable in $46.10 \%(\mathrm{n}=18 / 39)$, that is to say $55.50 \%$ of ICH $(\mathrm{n}=10 / 18)$ and $27.70 \%$ of SAH $(n=5 / 18)$. For the patients who died during the first week, 9 were before the 5th day, including 7 ICH and 2 SAH (Table 1).

From a brain scan point of view, with regard to the types of stroke, ICH's were found in $53.90 \%$ of cases $(n=21 / 39)$, followed by CI's with $n=13 / 39$ (33.30\%), and $\mathrm{SAH}$ in $12.80 \%$ of cases $(\mathrm{n}=5 / 39)$. Moreover, in $\mathrm{ICH}$ patients, intracerebral hematoma volumes greater than $30 \mathrm{~cm}^{3}$ were noted in 9 patients, that is to say $42.85 \%(n=9 / 21)$ (Table 2).

For biological data, the mean of concentration of plasma neuroglobin $(\mathrm{CmNgb})$ of the general population was $1.400 \pm 1.670 \mathrm{ng} / \mathrm{ml}$. In controls, it was $0.303 \pm 0.114 \mathrm{ng} / \mathrm{ml}$, compared to $3.140 \pm 2.700 \mathrm{ng} / \mathrm{ml}$ for stroke victims of all types. Of the 21 patients who presented ICH, $\mathrm{n}=10 / 21$ (47.64\%) had an ICH score $\geq 2 / 6$. In CI victim's, $76.90 \%(n=10 / 13)$ had a Four score $\geq 15 / 16$ (Table 2 ).

The comparison of the $\mathrm{CmNgb}$ of stroke victims with that of the controls at admission, its evolution over time as well as its relation with the epidemiological and clinical parameters including age, sex, history of arterial hypertension, the delay in the presumed occurrence of the initial symptoms of stroke, the Glasgow coma scale as well as the prognosis in the first week of admission, and the volume of intracerebral hematoma had been studied by the Spearman, Mann-Whitney and Wilcoxon tests.

Data from this analysis show that in controls, no relationship was found between $\mathrm{CmNgb}$ and age $(\mathrm{p}=0.070)$, sex $(1.020 \pm 1.810 \mathrm{ng} / \mathrm{ml}$ in men, and $1.300 \pm$ $1.200 \mathrm{ng} / \mathrm{ml}$ in women, $\mathrm{p}=0.975)$. In addition, there was no relationship between the existence of the history of arterial hypertension and $\mathrm{CmNgb}$ in patients $(\mathrm{p}=0.975)$. At the same time, there was a relationship between $\mathrm{CmNgb}$ collected from admission in subjects with stroke of any type, and the delay presumed occurrence of the first symptoms of stroke, especially, occurrence before the 6th hour, or after 6th hour following hospitalization $(0.643 \pm 0.244 \mathrm{ng} / \mathrm{ml}$ before $6 \mathrm{~h}$, against $3.140 \pm 2.700 \mathrm{ng} / \mathrm{ml}$ after $6 \mathrm{~h}, \mathrm{p}=0.003)$. Regarding the comparison of $\mathrm{CmNgb}$ between $\mathrm{CI}$ and ICH at hospitalization, it was $5.805 \pm 0.720$ $\mathrm{ng} / \mathrm{ml}$ in CI and $1.750 \pm 0.090 \mathrm{ng} / \mathrm{ml}$ in ICH $(\mathrm{p}=0.03)$ (Table 2).

About brain imaging, there is a relationship between the $\mathrm{CmNgb}$ and the volume of the hematoma. In fact, $\mathrm{CmNgb}$ was $2.161 \pm 0.375 \mathrm{ng} / \mathrm{ml}$ for hematomas with a volume greater than $30 \mathrm{~mm}^{3}$, compared with $1.210 \pm 0.752 \mathrm{ng} / \mathrm{ml}$ for those with a lower volume $(\mathrm{p}=0.0027)$.

There was no relationship between $\mathrm{CmNgb}$, mean of Glasgow coma scale ( $\mathrm{p}=$ $0.427)$ and outcome of patients during the first week of hospitalization $(p=0.06)$ (Table 2).

The study of the kinetics of CmNgb according to the type of stroke reveals that it was higher on $\mathrm{d} 1$ in the subjects with CI $(5.805 \pm 0.720 \mathrm{ng} / \mathrm{ml})$ than $\mathrm{ICH}$ $(1.750 \pm 0.090 \mathrm{ng} / \mathrm{ml})(\mathrm{p}=0.003)$. At $\mathrm{d} 3$, it was $2.602 \pm 0.112 \mathrm{ng} / \mathrm{ml}$ for CI and $0.420 \pm 0.211$ for ICH. At the 7 th day of hospitalization, it was $0.420 \pm 0.20$ $\mathrm{ng} / \mathrm{ml}(\mathrm{p}=0.001)$ in the victims of $\mathrm{CI}$, compared to $0.360 \pm 0.300 \mathrm{ng} / \mathrm{ml}$ in the ICH $(\mathrm{p}=0.002)($ Table 3$)$. 
Table 3. Comparison of CmNgb kinetics at day 1, day 3 and day 7 between CI (cerebral infarction) and ICH (intracerebral hemorrhage) victims.

\begin{tabular}{cccc}
\hline Kinetic (day) & $\begin{array}{c}\text { CI } \\
\text { CmNgb (ng/ml) }\end{array}$ & $\begin{array}{c}\text { ICH } \\
\text { CmNgb }(\mathrm{ng} / \mathrm{ml})\end{array}$ & $\mathrm{p}$ \\
\hline J1 & $5.800 \pm 0.720$ & $1.750 \pm 0.090$ & 0.003 \\
J3 & $2.600 \pm 0.600$ & $0.420 \pm 0.100$ & 0.001 \\
J7 & $0.420 \pm 0.200$ & $0.360 \pm 0.300$ & 0.002 \\
\hline
\end{tabular}

\section{Discussion}

\subsection{Limitations of Work}

The purpose of this prospective study was to evaluate the role of plasma Ngb in the initial diagnosis and short-term prognosis of adult stroke victims (infarction and hemorrhage), taking into account subgroups (CI or cerebral infarction, SHA or subarachnoid haemorrhage, ICH or intracerebral hematoma). To do this, we selected a convenience sample, consisting of stroke suspects (patients), selected consecutively over a one-year period, with direct match by age and sex to persons in good health (Volunteers). This investigation being a hospital series, we unfortunately ran into several difficulty. The most frequent were the difficulty of obtaining a brain scan (economical difficults, disponibility of imaging), before taking blood samples, the use of drugs that can modify the expression of Ngb by some clinicians [43], a significant number of refusals of consent, lost to follow-up, and to a lesser degree, the loss of some samples. These different facts resulted in reduced sample size, which inevitably impacted the composition of stroke subgroups. However, despite these limitations, our data show that in the acute phase of stroke, compared to controls, the plasma concentration of neuroglobin $(\mathrm{CmNgb})$ increases significantly regardless of the type of stroke ( $\mathrm{ICH}$ or CI). Moreover, this increase is greater in the case of ischemia than hemorrhage, and seems to follow a triphasic kinetics. Conversely, no relationship was found between Glasgow coma scale, short-term mortality and CmNgb. Similarly, we could not analyze the relationships between $\mathrm{CmNgb}$ and specific prognostic scores for stroke, particularly because of the size of the sample. In all cases, according to the other human studies of Ngb's expression during nervous system diseases, our data seem to support the idea that $\mathrm{Ngb}$ is overexpressed during hypoxic-ischemic states [1]-[10] [24] [26]. This expression of Ngb, like other biomarkers of nervous system (NS) [40] [41], would be more important during ischemia such as stroke [1] [2] [3] [11] [12] [13] [23] [24] [50]-[54]. Thus, our results suggest that, in human, plasma neuroglobin can be used as a bio-marker for initial diagnosis, but not for the short-term prognosis of acute adult stroke.

\subsection{Epidemiological and Clinical Parameters of the General Population, Stroke Subjects as well as Subgroups (CI and ICH)}

In our series, we noted more hemorrhagic than ischemic strokes (26 versus 13 ). These data are similar to those obtained by Adeloye et al. [28], Burgnicourt et al. 
[29], Ovbiagel et al. [31], and Eyang Biyoghe et al. [30]. However, other authors have found more CI than ICH [32]. These results could be explained by the existence of African populations, an arterial hypertension usually of early discovery, often poorly controlled, related to the male sex, geo ethnic and genetic factors [28] [29] [30] [31] [32].

Concerning the gender, men presented more hypertension than women. According to African studies, this result corroborates those found by several other authors [28]-[33]. This male predominance may be explained by the high frequency of some risk factors in men [28] [29] [31]. In contrast, the low prevalence observed in women is thought to be related to the hormonal cycle [55] [56].

The mean age of the stroke population in this investigation is relatively similar to that of the majority of African studies, with a peak frequency of ICH in younger people, one of the reasons of which would be early hypertension [28] [29] [30] [31] [32], which could explain why high blood pressure was the risk factor most found in our investigation. This predominance of hypertension is widely found in both Western and African literature [28]-[33] [57] [58] [59].

\subsection{Comparison of $\mathrm{CmNgb}$ between Stroke Victims and Controls, Relationship between CmNgb, Epidemiological, Clinical and Paraclinical Parameters of Stroke Subjects}

\section{$\mathrm{CmNgb}$ in the controls}

$\mathrm{Ngb}$ is a protein whose mechanisms can explain its presence at the plasma in physiological conditions as well as the standard of concentration (reference value) are not completely defined in humans [1] [2] [3] [12]. Thus, the recruitment of a population of healthy volunteers (controls) carried out during this work made it possible to obtain a control value of $\mathrm{CmNgb}(0.303 \pm 0.114 \mathrm{ng} / \mathrm{ml})$. However, this control $\mathrm{CmNgb}$ is not identical to that found by other authors. Indeed, in animals, Shang et al. [12] had conducted a study examining the dynamics of neuroglobin expression changes in the brain and serum at different times, before and after induction of cerebral ischemia and reperfusion in Mongolian gerbils. The mean concentration of neuroglobin found was $4.61 \pm 2.53$ $\mathrm{ng} / \mathrm{ml}$ before ischemia (healthy brain), with extremes of $1.42 \mathrm{ng} / \mathrm{ml}$ and 9.20 $\mathrm{ng} / \mathrm{ml}$. This value is 15 times greater than ours. In parallel, Brunori and Vallone, by immunohistochemical determination of $\mathrm{Ngb}$ in human cerebral parenchy main post mortem, had noted a value of $1 \mu \mathrm{mol} / 1$ into the brain tissue supposed healthy [60]. This difference between our results and those of Shang suggests that in terms of animal species, in physiological conditions, the human being would produce less $\mathrm{Ngb}$ or catabolize it faster. Compared to the values found by Brunori and Vallone [60], unfortunately, there is no validated data to date correlating plasma concentrations of neuroglobin and tissue Ngb levels detected by immunohistochemistry. 


\subsection{CmNgb and Mean of Age of the Working Population}

This study found no relationship between $\mathrm{CmNgb}$ and age, both in patients and controls $(\mathrm{p}=0.07$ ). Concerning the $\mathrm{CmNgb}$ and age, Sun et al. [61] noted, in physiological conditions, a decrease in the cerebral expression of neuroglobin as a function of age in rats aged respectively 3, 12 and 24 months. Moreover, this decrease predominated in the regions preferentially affected by neurodegeneration. The fact that our results are different from those of Sun et al would probably be due to the fact that in humans cerebral expression of $\mathrm{Ngb}$ is a function of areas of cerebral tolerance to hypoxia-ischemia syndrome. Indeed, according to some authors, there exist, in physiological situations and according to the age, regions of the central nervous system designated high and low tolerance to ischemia (cortex versus subcortical regions), hypoxia and the extent of metabolic demand [6] [7] [8] [12] [22] [26] [31] [32] [33] [34]. The neuroglobin is a molecule with anti-apoptotic and anti-hypoxic properties, the absence of variation in its concentration observed during our study may also be related to the relatively early age (18 - 65 years) of the sample [1] [2] [3].

\section{Relationship between $\mathrm{CmNgb}$ and sex}

Contrary at the study of Szymanski et al. [62] who showed that the expression of $\mathrm{Ngb}$ was relatively lower in female subjects compared to males, we found no statistically significant difference between men and women, both in controls and in stroke $(1.020 \mathrm{ng} / \mathrm{ml}$ versus $1.300 \mathrm{ng} / \mathrm{ml}, \mathrm{p}=0.975)$. One of the hypotheses that could explain the difference between our results and Szymanski's results would be methodological. Indeed, we have registered more men than women (ratio $\mathrm{M} / \mathrm{W}=2.5$ ). Another reason is that, unlike our work, which treat with stroke victims, Szymanski et al's research mainly treat with adult subjects suffering from Alzheimer's disease, whose onset is in part generally correlated with neurodegeneration, life experance and female sex [62].

\section{$>$ Comparison of stroke neuroglobinemia to that of controls}

At the end of the present investigation, it was found that in comparison with the controls, the CmNgb of stroke victims was higher regardless of the type (ischemic or hemorrhagic) $(\mathrm{p}=0.07)$. Stroke usually results from rupture (hemorrhage) or vascular obstruction (ischemia) which are responsible to the hypo infusion, hypoxia and cellular ischemia. These latter processes are themselves responsible for inflammation and cellular suffering [34] [35] [36]. Thereby, our results suggest that cerebral ischemia observed during stroke (ischemia or hemorrhage) induces Ngb expression, as has been demonstrated by many authors [1] [2] [3] [11] [12] [13] [23] [27] [50] [51] [52] [53] [54]. From these data, the absence of a significant difference in Cmgb that we noted between stroke and controls would be explained by the high number of ICH's compared to CI's in the stroke population (26/39 versus 13/39). In Africa, this high frequency of ICH compared to CI has already been found by other authors [30]. The brain scan is sometimes normal during early phase of CI [37] [38] [39], our result confirms the high expression of neuroglobin observated during stroke by many authors 
[1] [2] [3] [11] [12] [13] [23] [24] [50] [51] [52] [53] [54], and suggests that the plasma Ngb dosage may be a necessary for diagnostic guidance during this period. In that context, this dosage in association with clinic examination and brain scan could help to confirm or not the suspected cases of stroke in emergency situation [37] [38] [39].

Comparison of $\mathrm{CmNgb}$ taken at day 1 between subgroups of stroke victims ( $\mathrm{CI}$ and $\mathrm{ICH})$

Because the expression of $\mathrm{Ngb}$ is more important in CI's than ICH, our data suggest the probable existence of secondary ischemia in the peri-hematoma zone during ICH's, and thus confirm those of many authors [27] [35] [36] [50] [51] [52] [53]. This secondary ischemia, in the long run, would be the cause of hypoxia with activation of HIF-1 alpha [22] [23] [35] [36] which, in turn induce the release of neuroglobin [1] [2] [3] [6] [7] [9] [11]. Thus, the secondary occurrence of the cascade of events responsible for the $\mathrm{Ngb}$ brain expression (hypoxia, ischemia, apoptosis) during ICH compared to the CI (immediatly ischemia, no secondary occurrence) could explain the observed difference between the two groups. Therefore, like other biomarkers of stroke, $\mathrm{CmNgb}$ could be used as a diagnostic marker, differentiating ischemia from haemorrhage [38] [39] [40] [41]. Better still, in clinical practice, CmNgb would be used to differentiate, for example, ICH from intra cerebral hematoma resulting from hemorrhagic transformation of an ischemic stroke.

\section{> Comparison of $\mathrm{CmNgb}$ taken on admission and the presumed time of} appearance to first stroke symptoms in patients

We found a statistically significant relationship between the level of Ngb taken from admission in stroke and the presumed time of appearance to the first symptoms of the disease $(0.643 \mathrm{ng} / \mathrm{ml}$ before $6 \mathrm{~h}$, against $3.140 \mathrm{ng} / \mathrm{ml}$ after $6 \mathrm{~h}, \mathrm{p}$ $=0.003)$. In other terms, $\mathrm{CmNgb}$ varied with duration of stroke. This result is comparable to that of other authors [11] [12] [13] [27] [51] [53]. He would correspond to a progressive production of the $\mathrm{Ngb}$, and a fall of the latter, after a peak of production. Thus, despite the fact that we have not been able to monitor the $\mathrm{CmNgb}$ early (that is to say from the installation of the initial symptomatology until admission to the service), our results support the idea that elevation of CmNgb is a function of the duration of stroke [11] [12] [13] [14] [27] [50] [51] [52] [53]. This elevation of Ngb in the acute phase of stroke may be explained by the ischemic nature of the initial lesion and/or because stroke (ischemic or hemorrhagic) is usually complicated by initial or secondary cerebral ischemia, with cell lysis, favoring the progressive overexpression of $\mathrm{Ngb}$ at the cerebral level and secondarily the release in the plasma [24] [27] [35] [36] [50] [51] [52] [53]. In this case, this result suggests $\mathrm{CmNgb}$ as a biological element of monitoring, at least during the early and critical phase of stroke [11] [12] [13].

Relationship between volume of intracerebral hematoma and $\mathrm{CmNgb}$ in ICH victims

At the end of our study, we observed that the concentrations of Ngb were higher in subjects with a hematoma volume greater than $30 \mathrm{~cm}^{3}(\mathrm{p}=0.027)$. 
Thus, our results suggest that there is a direct relationship between Ngb, with ischemia of which it would be partly the consequence. Despite the fact that these data corroborate those of several other studies [24] [27] [35] [36] [50] [51] [52] [53], they are however in contradiction with those of Sun et al. [1] [2] [3] [13]. Indeed, these authors suggested that the increase of $\mathrm{Ngb}$ was inversely proportional to the size of the ischemic lesions in the rodent. These contradictory results would be explained by the fact that the data of the above mentioned studies are, on the one hand immunohistochemical in nature, and on the other hand, do not give any precision as to the exact relationship between the kinetics of the concentration of $\mathrm{Ngb}$ and the lesion volume. To a lesser degree, the absence of CT brain monitoring that could re-evaluate the volume of the lesion would be another reason for this absence of similarity of our results with those of others

\subsection{Relationship between CmNgb, Prognostic Scores (Glasgow, Hemphill, WFNS, Fisher, Four) and Short-Term Mortality Collected on Admission in Stroke Subjects}

Relationship between the prognostic scores of stroke and $\mathrm{CmNgb}$ collected on admission in stroke subjects

There was no relationship between Glasgow coma scale at the admission in stroke and the $\mathrm{CmNgb}(\mathrm{p}=0.427)$. The Glasgow coma scale assesses the level of consciousness in comatose patients, without presaging etiology [44]. Moreover, when it is performed on admission, it contributes to the establishment of the neurological prognosis of the patient. In this case, our results might suggest that the Ngb has no prognostic interest and would still allow less to assess the state of consciousness. However, this score is not very specific and not very sensitive in the context of the strokes, from where besides the setting of specific scores by many authors [45] [46] [47] [48]. In this case, another explanation for the absence of relationship of this score with the $\mathrm{CmNgb}$ is the fact of its low sensitivity and specificity during stroke [45] [46] [47] [48]. Finally, the weakness of the sample size of patients with a low Glasgow score would also be a reason.

At the same time, probably because of the size of the sample, no relationship could be analyzed between the specific gravity scores of the stroke (ICH Hemphill score for intracerebral hematoma, WFNS and Fisher scores for SAH, FOUR score for $\mathrm{CI}$ ) and $\mathrm{CmNgb}$. Thus, in the African context, a study of Ngb variation in hemorrhagic stroke involving a large sample of patients and taking into account subgroups of ICH is desirable.

\section{$\mathrm{CmNgb}$ and short-term mortality in stroke}

It has not been found none relationship between $\mathrm{Ngb}$ on admission and short-term mortality $(p=0.06)$. However, it was noted that, although the difference was not statistically significant, patients who survived had higher plasmatic $\mathrm{Ngb}$ concentration compared to those who died ( $3.95 \mathrm{ng} / \mathrm{ml}$ versus $2.65 \mathrm{ng} / \mathrm{ml}$ ). Despite the fact that current studies on Ngb are not specifically focused on mortality, some authors have found that Ngb overexpression is associated with im- 
proved ischemic injury and functional recovery in rodents [1] [2] [3] [52] [53]. In addition, plasma levels of neuroglobin would be proportional to the intensity of apoptotic activity and the degree of cell necrosis [1] [2] [3].

\subsection{Kinetics of CmNgb Collected at d1, d3 and $\mathrm{d} 7 \mathrm{in} \mathrm{CI}$ and ICH Patients}

Regarding the specific kinetics of $\mathrm{Ngb}$ as a function of the evolution of stroke, it was noted that the $\mathrm{CmNgb}$, after an elevation phase, was reduced by half to $\mathrm{d} 3$ and became almost normal on $\mathrm{d} 7$, whatever the type of stroke. In the case of cerebral infarctions, this kinetics of Ngb was also found by Shang et al. in 2006 [14]. However, in this study, the concentration of Ngb was still significantly elevated at $72 \mathrm{~h}(11.94 \mathrm{ng} / \mathrm{ml}$ versus $2.60 \mathrm{ng} / \mathrm{ml}$ for this study). This could be explained by the fact that these studies were conducted in rats and not humans. In addition, methodologically, rodent experimentation consisted of bilateral carotid occlusion for 20 minutes, resulting in more lesions than under physiological conditions. Another explanation would be that our patients were mostly hypertensive and were receiving rheological treatment to prevent ischemia from increasing.

Regarding to ICH, the same triphasic kinetics was noted by Dongsheng et al. [50], as well as Wei-de et al. [51]. According to the latter, this over expression would pathophysiologically reflect the secondary ischemia occurring in the peri-hematoma zone, and confirm the neuroprotective role of Ngb during the immediate phase of neuronal injury during ICH [50] [51], but also other spathologies of NS [1] [2] [3] [6] [7] [10] [14] [15] [16] [17] [23] [24] [26] [27]. In our opinion, this result suggests that plasma neuroglobin may play a role as a biomarker for early monitoring during the acute phase of stroke.

\section{Conclusion}

The present prospective study was designed to assess the role of plasma Ngb in the initial diagnosis and short-term prognosis of adult stroke victims. It emerges that, at the acute phase of a stroke, in comparison with that of controls, CmNgb increases significantly regardless of the type (ICH or CI). Moreover, this increase is greater in the case of ischemia than hemorrhage, and has a triphasic kinetics. In contrast, no relationship was found between the Glasgow coma scale, short-term mortality and $\mathrm{CmNgb}$. In addition, no relationship could be analyzed between $\mathrm{CmNgb}$ and the usual prognostic scores of stroke subgroups. Thus, our results suggest that in human, neuroglobin plasmatic can be used as a diagnostic, but not prognostic biomarker for stroke in adults at the acute phase. However, this work needs to be confirmed on a larger sample of stroke taking into account the different subgroups.

\section{Conflicts of Interest}

The authors declare no conflicts of interest regarding the publication of this paper. 


\section{References}

[1] Xie, L.K. and Yan, S.H. (2016) Brain Globins in Physiology and Physiopathology. Medical Gas Research, 6, 154-163. https://doi.org/10.4103/2045-9912.191361

[2] Baez, E., Echeverria, V., Cabezas, R., Avila-Rodriguez, M., Garcia-Segura, L.M., et al. (2016) Protection by Neuroglobin Expression in Brain Pathologies. Frontiers in Neurology, 7, 1-9. https://doi.org/10.3389/fneur.2016.00146

[3] Ascenzi, P., di Masi, A., Leboffe, L., Fiocchetti, M., Nuzzo, M.T., et al. (2016) Neuroglobin: From Structure to Function in Health and Disease. Molecular Aspects of Medicine, 52, 1-48. https://doi.org/10.1016/j.mam.2016.10.004

[4] Duong, T.T.H., Witting, P.K., Antao, S.T., Parry, S.N., Kennerson, M., et al. (2009) Multiple Protective Activities of Neuroglobin in Cultured Neuronal Cells Exposed to Hypoxia Re-Oxygenation Injury. Journal of Neurochemistry, 108, 1143-1154. https://doi.org/10.1111/j.1471-4159.2008.05846.x

[5] Oliveira, K.C., da Conceição, R.R., Piedade, G.C., de Souza, J.S., Sato, M.A., et al. (2015) Thyroid Hormone Modulates Neuroglobin and Cytoglobin in Rat Brain. Metabolic Brain Disease, 30, 1401-1408. https://doi.org/10.1007/s11011-015-9718-5

[6] Schneuer, M., Flachsbarth, S., Czech-Damal, N.U., Folkow, L.P., Siebert, U., et al. (2012) Neuroglobin of Seals and Whales: Evidence for a Divergent Role in the Diving Brain. Neuroscience, 223, 35-44.

https://doi.org/10.1016/j.neuroscience.2012.07.052

[7] Van Leuven, W., Van Dam, D., Moens, L., De Deyn, P.P. and Dewilde, S. (2013) A Behavioural Study of Neuroglobin-Overexpressing Mice under Normoxic and Hypoxic Conditions. Biochimica et Biophysica Acta, 1834, 1764-1771. https://doi.org/10.1016/j.bbapap.2013.04.015

[8] Greenberg, D.A., Jin, K. and Khan, A.A. (2008) Neuroglobin. An Endogenous Neuroprotectant. Current Opinion in Pharmacology, 8, 20-24.

https://doi.org/10.1016/j.coph.2007.09.003

[9] Avivi, A., Gerlach, F., Joel, A., Reuss, S., Burmester, T., et al. (2010) Neuroglobin, Cytoglobin, and Myoglobin Contribute to Hypoxia Adaptation of the Subterranean Mole Rat Spalax. Proceedings of the National Academy of Sciences of the United States, 107, 21570-21575. https://doi.org/10.1073/pnas.1015379107

[10] Ovono Abessolo, F., Atsame Minko, P. and Nnang Essone, J.F. (2016) Neuroglobine et souffrance fœtale aigue: Y a-t-il une relation entre la neuroglobine et les marqueurs classiques de la souffrance fotale aigue? Presses Académiques Francophones, Wroclaw, $68 \mathrm{p}$.

[11] Jin, K., Mao, Y., Mao, X., Xie, L. and Greenberg, D.A. (2010) Neuroglobin Expression in Ischemic Stroke. Stroke, 41, 557-559. https://doi.org/10.1161/STROKEAHA.109.567149

[12] Shang, A., Zhou, D. and Wang, L. (2006) Increased Neuroglobin Levels in the Cerebral Cortex and Serum after Ischemia-Reperfusion Insults. Brain Research, 1078, 219-226. https://doi.org/10.1016/j.brainres.2006.01.064

[13] Sun, Y., Kunlin, J., Peel, A., Mao, X.O., Xie, L. and Greenberg, D.A. (2003) Neuroglobin Protects the Brain from Experimental Stroke in Vivo. Proceedings of the National Academy of Sciences of the United States, 100, 3497-3500. https://doi.org/10.1073/pnas.0637726100

[14] Lechauve, C., Augustin, S. and Roussel, D. (2013) Neuroglobin Involvement in Visual Pathways through the Optic Nerve. Biochimica et Biophysica Acta, 1834, 1772-1778. https://doi.org/10.1016/j.bbapap.2013.04.014 
[15] Wei, X., Yu, Z. and Cho, K.S. (2011) Neuroglobin Is an Endogenous Neuroprotectant for Retinal Ganglion Cells against Glaucomatous Damage. The American Journal of Pathology, 179, 2788-2797. https://doi.org/10.1016/j.ajpath.2011.08.015

[16] Chan, A.S., Saraswathy, S. and Rehak, M. (2012) Neuroglobin Protection in Retinal Ischemia. Investigative Ophthalmology \& Visual Science, 53, 704-711. https://doi.org/10.1167/iovs.11-7408

[17] Ueki, M., Saraswathy, S. and Rao, N.A. (2012) Neuroglobin Protects Retinal Neurons in Ischemia/Reperfusion Injury. Investigative Ophthalmology \& Visual Science, 53, 704-711. https://doi.org/10.1167/iovs.11-7408

[18] Jayaraman, T., Tejero, J., Chen, B.B., Blood, A.B., Frizzell, S., et al. (2011) 14-3-3 Binding and Phosphorylation of Neuroglobin during Hypoxia Modulate Six-to-Five Heme Pocket Coordination and Rate of Nitrite Reduction to Nitric Oxide. The Journal of Biological Chemistry, 286, 42679-42689.

https://doi.org/10.1074/jbc.M111.271973

[19] Liu, J., Yu, Z., Guo, S., Lee, S.-R. and Xing, C. (2009) Effects of Neuroglobin Overexpression on Mitochondrial Function and Oxidative Stress Following Hypoxia/Reoxygenation in Cultured Neurons. Journal of Neuroscience Research, 87, 164-170. https://doi.org/10.1002/jnr.21826

[20] Raychaudhuri, S., Skommer, J., Henty, K., Birch, N. and Brittain, T. (2010) Neuroglobin Protects Nerve Cells from Apoptosis by Inhibiting the Intrinsic Pathway of Cell Death. Apoptosis, 15, 401-411. https://doi.org/10.1007/s10495-009-0436-5

[21] Antao, S.T., Duong, T.T.H., Aran, R. and Witting, P.K. (2010) Neuroglobin Overexpression in Cultured Human Neuronal Cells Protects against Hydrogen Peroxide Insult via Activating Phosphoinositide-3 Kinase and Opening the Mitochondrial $\mathrm{K}$ ATP Channel. Antioxidants \& Redox Signaling, 13, 769-781. https://doi.org/10.1089/ars.2009.2977

[22] Woo, S.K., Kwon, M.S., Geng, Z., Chen, Z., Ivanov, A., et al. (2012) Sequential Activation of Hypoxia-Inducible Factor 1 and Specificity Protein 1 Is Required for Hypoxia-Induced Transcriptional Stimulation of Abcc 8. Journal of Cerebral Blood Flow \& Metabolism, 32, 525-536. https://doi.org/10.1038/jcbfm.2011.159

[23] Zhao, S., Yu, Z., Zhao, G., Xing, C., Hayakawa, K., et al. (2012) Neuroglobin-Overexpression Reduces Traumatic Brain Lesion Size in Mice. BMC Neuroscience, 13, 67. https://doi.org/10.1186/1471-2202-13-67

[24] Taylor, J.M., Kelley, B., Gregory, E.J. and Berman, N.E.J. (2014) Neuroglobin Overexpression Improves Sensorimotor Outcomes in a Mouse Model of Traumatic Brain Injury. Neuroscience Letters, 577, 125-129.

https://doi.org/10.1016/j.neulet.2014.03.012

[25] Lin, Y., Fang, L., Xue, X.H., Murong, S.X., Wang, N., et al. (2008) Association between Ngb Polymorphisms and Ischemic Stroke in the Southern Chinese Han Population. BMC Medical Genetics, 9, 110.

https://doi.org/10.1186/1471-2350-9-110

[26] Purushothuman, S. and Stone, J. (2015) The Reaction of Cerebral Cortex to a Nearby Lesion: Damage, Survival, Self-Protection. Brain Research, 1601, 52-63. https://doi.org/10.1016/j.brainres.2015.01.003

[27] Yu, Z., Liu, N., Liu, J., Yang, K. and Wang, X. (2012) Neuroglobin, a Novel Target for Endogenous Neuroprotection against Stroke and Neurodegenerative Disorders. International Journal of Molecular Sciences, 13, 6995-7014. https://doi.org/10.3390/ijms13066995 
[28] Adeloye, D. (2014) An Estimate of the Incidence and Prevalence of Stroke in Africa: A Systematic Review and Meta-Analysis. PLoS ONE, 9, e100724. https://doi.org/10.1371/journal.pone.0100724

[29] Bugnicourt, J.M., Tchouata-Ngandjouc, L., Beugre, K., Chillon, J.M. and Godefroy, O. (2013) Comparaison des caractéristiques cliniques et de la prise en charge des accidents vasculaires cérébraux entre une population africaine (Abidjan) et une population française Amiens, une étude observationnelle. Revista de Neurología (Paris), 169, 258-265. https://doi.org/10.1016/j.neurol.2012.07.024

[30] Eyang Biyoghe, A., Obame, R., Nzoghé Nguema, P., Eyang Nkiet, S., Tchuinkam, A., et al. (2014) Etude de la prévalence des accidents vasculaires cérébraux dans les services d'accueil des urgences de l'Hôpital Universitaire d'Angondjé. RAMUR, 19 , 49.

[31] Ovbiagel, B., et al. (2017) Stroke in Indigenous Africans, African Americans, and European Americans. Stroke, 48, 1169-1175. https://doi.org/10.1161/STROKEAHA.116.015937

[32] Kouna Ndouongo, P., Millogo, A., Siéméfo Kamgang, F.D.P. and Assengone-Zhe, Y. (2007) Aspects épidémiologiques et évolutifs des accidents vasculaires au centre hospitalier de Libreville (Gabon). African Journal of Neurological Sciences, 26, 12-17.

[33] Zenebe, G., Alemayehu, M. and Asmera, J. (2005) Characteristics and Outcomes of Stroke at Tikur Anbessa Teaching Hospital, Ethiopia. Ethiopian Medical Journal, 43, 251-259.

[34] Sacco, R.L., et al. (2013) An Updated Definition of Stroke for the 21st Century. A Statement for Healthcare Professionals from the American Heart Association/American Stroke Association. Stroke, 44, 2064-2089. https://doi.org/10.1161/STR.0b013e318296aeca

[35] Jiménez, M.C., Rexrode, K.M., et al. (2016) Association between Markers of Inflammation and Total Stroke by Hypertensive Status among Women. American Journal of Hypertension, 29, 1117-1124. https://doi.org/10.1093/ajh/hpw050

[36] Smith, C.J., et al. (2018) Scil-Stroke (Subcutaneous Interleukin-1 Receptor Antagonist in Ischemic Stroke). A Randomized Controlled Phase 2 Trial. Stroke, 49, 1210-1216. https://doi.org/10.1161/STROKEAHA.118.020750

[37] El Machkour, M., Chtaou, N., Maaroufi, M. and Belahsen, F. (2011) Imagerie de l'accident vasculaire cérébral ischémique à la phase aiguë. Le Journal Marocain de Cardiologie, 3, 24-32.

[38] Laskowitz, D.T., Kasner, S.E., Saver, J., Remmel, K.S. and Jauch, E.C. (2009) Clinical Usefulness of a Biomarker-Based Diagnostic Test for Acute Stroke: The Biomarker Rapid Assessment in Ischemic Injury (BRAIN) Study. Stroke, 40, 77-85. https://doi.org/10.1161/STROKEAHA.108.516377

[39] Vanni, S., Polidori, G. and Pepe, G. (2011) Use of Biomarkers in Triage of Patients with Suspected Stroke. Journal of Emergency Medicine, 40, 499-505. https://doi.org/10.1016/j.jemermed.2008.09.028

[40] Delgado, P., Sabin, J.A. and Santamarina, E. (2006) Plasma S100 $\beta$ Level after Acute Spontaneous Intra Cerebral Hemorrhage. Stroke, 37, 2837-2839. https://doi.org/10.1161/01.STR.0000245085.58807.ad

[41] Fowler, S.B. and Mancini, B. (2007) Predictive Value of Biochemical Markers in Stroke. Journal of Neuroscience Nursing, 39, 58-60. https://doi.org/10.1097/01376517-200702000-00011 
[42] World Health Organization (2013) World Medical Association Declaration of Helsinki. Ethical Principles Applicable to Medical Research Involving Human Beings. http://www.wma.net/fr

[43] Jin, K., Mao, X.O., Xie, L., John, V. and Greenberg, D.A. (2011) Pharmacological Induction of Neuroglobin Expression. Pharmacology, 87, 81-84. https://doi.org/10.1159/000322998

[44] Teasdale, G. and Jennett, B. (1975) Assessment of Coma and Impaired Consciousness. The Lancet, 304, 1245-1250.

[45] Wijdicks, E.F., Bamlet, W.R., Maramattom, B.V., Manno, E.M. and McClelland, R.L. (2005) Validation of a New Coma Scale: The Four Score. Annals of Neurology, 58, 585-593. https://doi.org/10.1002/ana.20611

[46] Teasdale, G.M., Drake, C.G., Hunt, W., Kassell, N., Sano, K., et al. (1988) A Universal Subarachnoid Hemorrhage Scale: Report of a Committee of the World Federation of Neurosurgical Societies. Journal of Neurology, Neurosurgery, and Psychiatry, 51, 1457. https://doi.org/10.1136/jnnp.51.11.1457

[47] Fischer, U., Nedeltchev, K., Gralla, J., Brekenfeld, C. and Arnold, M. (2008) Thromboses veineuses cérébrales: Mise à jour. Curriculum Forum Médical Suisse, 8, 766-772. https://doi.org/10.4414/fms.2008.06617

[48] Hemphil 3rd, J.C., Bonovich, D.C., Besmertis, L., Manley, G.T. and Johnsston, S.C. (2001) The ICH Score: A Simple, Reliable Grading Scale for Intra Cerebral Hemorrhage. Stroke, 32, 891-897. https://doi.org/10.1161/01.STR.32.4.891

[49] Elabscience ${ }^{\oplus}$. http://www.elabscience.com

[50] Pan, D.-S., Wei, X.-Z., Feng, X.-L. and Feng, S.-Z. (2006) Expression of Neuroglobin in Brain Tissue of Rats with Intra-Cerebral Hemorrhage. Chinese Journal of Clinical Rehabilitation, 10, 97-99.

[51] Li, W.D., Sun, Q., Zhang, X.S., Wang, C.X., Li, S., Li, W. and Hang, C.H. (2014) Expression and Cell Distribution of Neuroglobin in the Brain Tissue after Experimental Subarachnoid Hemorrhage in Rats: A Pilot Study. Cellular and Molecular Neurobiology, 34, 247-255. https://doi.org/10.1007/s10571-013-0008-7

[52] Wang, X., Liu, J., Zhu, H., Tejima, E., Tsuji, K., Murata, Y., et al. (2008) Effects of Neuroglobin Overexpression on Acute Brain Injury and Long-Term Outcomes after Focal Cerebral Ischemia. Stroke, 39, 1869-1874. https://doi.org/10.1161/STROKEAHA.107.506022

[53] Raida, Z., Hundahl, C.A., Nyengaard, J.R. and Hay-Schmidt, A. (2013) Neuroglobin Overexpressing Mice: Expression Pattern and Effect on Brain Ischemic Infarct Size. PLoS ONE, 8, e76565. https://doi.org/10.1371/journal.pone.0076565

[54] Khan, A.A., Wang, Y. and Sun, Y. (2006) Neuroglobin-Overexpressing Transgenic Mice Are Resistant to Cerebral and Myocardial Ischemia. Proceedings of the National Academy of Sciences of the United States, 103, 17944-17948. https://doi.org/10.1073/pnas.0607497103

[55] Appelros, P., Stegmayr, B. and Terent, A. (2009) Sex Differences in Stroke Epidemiology: A Systematic Review. Stroke, 40, 1082-1090. https://doi.org/10.1161/STROKEAHA.108.540781

[56] Dehlendorff, C., Kaae Andersen, K. and Skyhøj Olsen, T. (2015) Sex Disparities in Stroke: Women Have More Severe Strokes But Better Survival than Men. Journal of the American Heart Association, 4, e001967. https://doi.org/10.1161/JAHA.115.001967

[57] Shook, R.P., Prasad, V., Hooker, S.P., Church, T.S., et al. (2012) Cardiorespiratory 
Fitness Reduces the Risk of Incident Hypertension Associated with a Parental History of Hypertension. Hypertension, 59, 1220-1224. https://doi.org/10.1161/HYPERTENSIONAHA.112.191676

[58] Flossmann, E. and Rothwell, P.M. (2005) Family History of Stroke in Patients with Transient Ischemic Attack in Relation to Hypertension and Other Intermediate Phenotypes. Stroke, 36, 830-835. https://doi.org/10.1161/01.STR.0000158920.67013.53

[59] Seth, A., Mossavar-Rahmani, Y., Kamensky, V., Silver, B., et al. (2014) Potassium Intake and Risk of Stroke in Women with Hypertension and Nonhypertension in the Women's Health Initiative. Stroke, 45, 2874-2880. https://doi.org/10.1161/STROKEAHA.114.006046

[60] Brunori, M. and Vallone, B. (2006) A Globin for the Brain. The FASEB Journal, 20, 2192-2197. https://doi.org/10.1096/fj.06-6643rev

[61] Sun, Y., Jin, K. and Mao, X.O. (2005) Effect of Aging on Neuroglobin Expression in Rodent Brain. Neurobiology of Aging, 26, 275-278. https://doi.org/10.1016/j.neurobiolaging.2004.03.006

[62] Szymanski, M., Wang, R., Fallin, M.D., Bassett, S.S. and Avramopoulos, D. (2010) Neuroglobin and Alzheimer's Dementia: Genetic Association and Gene Expression Changes. Neurobiology of Aging, 31, 1835-1842.

https://doi.org/10.1016/j.neurobiolaging.2008.10.003

[63] Alz.org Research Center.

http://www.alz.org/research/science/alzheimers_disease_causes.asp 